\title{
Perspectives of children with disabilities and their guardians on factors affecting inclusion in education in rural Nepal: "I feel sad that I can't go to school"
}

Authors: Lena Morgon Banks ${ }^{1}$ Maria Zuurmond ${ }^{1}$, (joint first authors), Adrienne Monteath-Van Dok ${ }^{2}$, Jaquelline Gallinetti ${ }^{3}$, Nidhi Singal ${ }^{4}$

1.Lena Morgon Banks \& Maria Zuurmond: Research Fellows, International Centre for Evidence in Disability, London School of Hygiene and Tropical Medicine, Keppel Street London .Corresponding author: Morgon.banks@lshtm.ac.uk

2.Adrienne Monteath-Van Dok, Director at Peace Direct

3. Jaquelline Gallinetti: Director of Research and Knowledge Management, Plan International,

4. Dr Nidhi Singal :Senior Lecturer in Inclusive Education, Faculty of Education, University of Cambridge, UK

\section{Abstract}

Globally, children with disabilities are significantly less likely to attend school compared to their peers without disabilities and, even if they do attend, have poorer educational outcomes. In order to understand why these inequalities persist, this study explores the barriers and enablers to accessing education, including not only school attendance but also the quality of the learning and social experience while at school. We focus on the perspectives of guardians and children with disabilities themselves - voices that have thus far been underrepresented - complemented by perspectives from local and national level stakeholders. Data was collected in three rural districts in Nepal, using semi-structured interviews; data was analysed thematically. Overall, the research found that challenges to inclusion are complex, involving a mixture of individual, family, school, community and policy level factors. Notable barriers were attitudes towards education for children with disabilities, the low capacity of schools to provide an inclusive education, as well as the interplay of additional 'push factors' such as poor health and poverty.

Key Words: Disability; Inclusive Education, Nepal, Barriers, Enablers, Caregivers, Children 


\section{INTRODUCTION}

Globally, there has been impressive progress on improving access to education. Due in part to the political commitments advanced through the Millennium Development Goals and the Education for All (EFA) initiative, net enrolment in primary school rose from 83\% in 2000 to $91 \%$ in 2015 (United Nations, 2018). However, it is estimated that 57 million primary school-aged children worldwide still remain out of school and improving the quality of education has been recognised as a pressing concern (United Nations, 2015, 2018).

Additionally, gains in improving access to education have not been shared equally. Notably, children with disabilities still face widespread exclusion from education (N. E. Groce \& Trani, 2009; UNESCO, 2010; WHO \& World Bank, 2011). In low- and middle-income countries (LMICs), children with disabilities are less likely to start school, have lower rates of school attendance, and lower transition rates to higher levels of education (Filmer, 2008; N. Groce et al., 2011; Mitra, Posarac, \& Vick, 2013; Mizunoya, Mitra, \& Yamasaki, 2016; WHO \& World Bank, 2011). For example, a recent analysis revealed that across 30 countries, children with disabilities were on average ten times less likely to attend school than children without disabilities and even when they did attend, their level of schooling was below that of their peers (Kuper et al., 2014). The influence of disability on school attendance has been shown to be stronger than that of other factors linked to limited participation in education (WHO \& World Bank, 2011).

While enrolment has increased for children with certain impairments types in some LMICs, the overall quality of educational experiences for children with disabilities remains poor (N. Singal \& R. Jeffery, 2011). This is evident from research demonstrating how children with disabilities remain excluded from the 
curriculum and culture of mainstream settings (Barriga, 2011; Nidhi Singal, 2008). In addition to an isolating school experience, the failure to provide an inclusive learning and social environment may also contribute towards understanding why school attendance does not always translate neatly into greater employment opportunities for young adults with disabilities (N Singal, Bhatti, \& Janjua, 2012).

Improving access to education for children with disabilities - in terms of enrolment, attainment, and quality of learning - has increasingly become a mainstream development concern, reflected in Goal 4 of the 2030 Sustainable Development Goals (SDGs), which seeks to "ensure an inclusive and equitable quality education...for all" (United Nations, 2015). SDG 4 Targets and Indicators reinforce the need to measure equity in enrolment and attainment by disability (Target 4.5), as well as ensure learning environments are disability-inclusive (Target 4.A). The right of children with disabilities to education on an equal basis with others is also codified in the Universal Declaration of Human Rights (Article 26), the Convention on the Rights of the Child (Articles 23, 28, 29) and the United Nations Convention on the Rights of Persons with Disabilities (UNCRPD) (Article 24). The latter mandates that states ensure access for children with disabilities to an inclusive, quality education, and provide reasonable accommodation and individualised support to foster academic and social development.

A significant body of research in the area of inclusive education in Southern contexts has focused on making a case for why inclusive education is critical for development (Miles \& Singal, 2010); has taken the form of conceptual analyses of terms such as integration, mainstreaming and inclusive education (Sharma \& Das, 2015); and focused disproportionally on examining the attitudes of teachers and other stakeholders towards children with disabilities (N. Singal, Ware, \& Khanna- 
Bhutani, 2017). While children with disabilities continue to be excluded, there is a need for a more context-specific and nuanced analysis of why these disparities in educational access and transition exist.

The research discussed in this paper contributes to furthering our understanding of the factors impacting access to an "inclusive and equitable quality education" for children with disabilities. More crucially, it contributes by giving the perspectives of children with disabilities and their guardians, which are currently lacking in the literature [15]. This research predominantly explores both barriers and facilitators (which do not always get highlighted), at the individual-, household- and community-levels, with some consideration of their contextualisation within an overarching policy environment.

\section{Policy and provision of education for children with disabilities in Nepal}

Policies on the education of children with disabilities in Nepal have undergone rapid changes in recent years. In addition to national laws and policies governing the provision of education, Nepal has also endorsed various international treaties and frameworks on education and disability, including the UNCRPD, SDGs and the EFA. While these laws and policies provide a legal framework supporting inclusive education, gaps in implementation have been noted (Barriga, 2011; UNICEF, 2016).

Under article 31 of Nepal's recently enacted Constitution (2015) basic education (primary and lower secondary - up to grade 8) is to be provided free of cost to all children, including specialised instruction (e.g. Braille, sign language) (Government of Nepal, 2015). Other laws and policies reaffirming the right of children with disabilities to free and inclusive education include: The Education Act 
(1971) and its amendments, the Disabled Protection and Welfare Act 1982, and the Special Education Policy (1997).

Additionally, the School Sector Reform Programme (SSRP) 2009-2015 was established to foster greater access to, equality in and quality of the educational system, in line with EFA and MDGs (Ministry of Education of the Government of Nepal, 2009). To promote the inclusion of children with disabilities, SSRP mandates the creation of "enabling conditions in every school" and the expansion of disabilitytargeted scholarships (Ministry of Education of the Government of Nepal, 2009). The National Policy and Plan of Action on Disability (2006) then provides for further supports such as the extension of free education for children with disabilities to cover pre-primary through to higher education, and highlights the need to improve accessibility of the physical environment, learning materials and teaching methods (Government of Nepal, 2006).

As part of the move towards more inclusive education, integrated schools were piloted in 2006 and have now spread across the country as a means of increasing educational opportunities for children with disabilities (Barriga, 2011). In these schools, children with specific types of impairment are taught in separate "resource classes" within a mainstream school. After developing skills such as sign language or Braille, the goal is to transfer children with disabilities into general classes. Special schools also provide impairment-specific instruction, and with the limited capacity of special and integrated schools, many children with disabilities attend regular mainstream schools (Lamichhane, 2013). Although the Special Education Policy (1996) stipulates arrangements must be made to allow children with disabilities to attend mainstream schools, additional support and resources are rarely available in these settings (Barriga, 2011; Lamichhane, 2013). In 2015, it was 
estimated that 4,000 students with disabilities were supported through 365 resource classes $-5.6 \%$ of the estimated 73,984 children with disabilities enrolled in school, or $2.2 \%$ of all children with disabilities (Eide, Neupane, \& Hem, 2016).

While the Ministry of Education is responsible for the overall development of educational policies and programmes - with the Special Education Council dedicated to inclusive education provisions - implementation and oversight falls to the District Education Offices in each of Nepal's 75 districts (Barriga, 2011). The District Education Office works through resource centres, which are responsible for the capacity building of schools in the area. Resource centres monitor schools under their jurisdiction as well as organize training for teachers. The training includes 45days of disability-specific instruction for teachers at integrated schools, which are mandatory for resource classroom teachers.

\section{Children with disabilities and education in Nepal: current state of}

\section{knowledge}

It is widely acknowledged that there is a lack of good quality data on disability in Nepal and the inadequacy of data and information constrains policy formulation and planning for the education of children with disabilities. Using a subset of data from the 2011 Census, disability prevalence in school-age children was estimated at $1.1 \%$ (UNICEF, 2016), which is low when compared to global estimates of $5.1 \%$ prevalence of childhood disability (WHO \& World Bank, 2011).

The EFA 2001-2015 National Review Report for Nepal highlighted that Nepal had met or was on track to meet many of its targets on EFA indicators such as increasing enrolment in primary school and reducing gender inequalities (UNESCO \& Government of Nepal, 2015). However, it noted that children with disabilities still 
faced large gaps in educational access. In an analysis by UNICEF using a subset of the 2011 Census data, it was estimated that $30.6 \%$ of children with disabilities (ages 5-12) were not attending school (UNICEF, 2016). Disability was one of the strongest predictors of being out-of-school, second only to belonging to the poorest socioeconomic quintile. Similarly, a recent national survey found about two-thirds of children with disabilities were attending school, compared to over $95 \%$ of children without disabilities (Eide et al., 2016).

Available data suggest enrolment differs amongst children with disabilities. For example, school attendance varied by impairment type, with the highest out-ofschool rates for children with multiple (52.5\%), intellectual (38.0\%), mental $(47.1 \%)$ and voice/speech (33.2\%) impairments (UNICEF, 2016). Additionally, boys with disabilities were more likely to be attending school compared to girls with disabilities (Eide et al., 2016; UNICEF, 2016). Further, children in rural areas were less likely to enrol in school compared to children with disabilities in urban areas (UNICEF, 2016).

Notable barriers highlighted in the literature are issues such as poor accessibility of facilities, lack of transport, lack of capacity of schools and teachers, limited resources, attitudes and low level of awareness amongst guardians about the educational opportunities for their children (Barriga, 2011; Cambridge Education Ltd \& METCON Consultants, April 2009; Lamichhane, 2013; UNICEF, 2016). Poor educational outcomes among children with disabilities in turn have been linked to lower employment and persistent poverty in Nepal (Lamichhane \& Okubo, 2014; Lamichhane \& Sawada, 2013). Still, most of these studies centre on the perspectives of government officials, teachers or disabled person's organizations (DPOs), with few incorporating the perspective of children and their guardians, which is the focus of this study. 


\section{METHODOLOGY}

We undertook a qualitative study to investigate the lived experiences of children with disabilities, and their experience in accessing education. We conducted semi-structured interviews with both children and their guardians and additionally conducted observational school visits and interviews with stakeholders which provided contextual background information, and allowed triangulation of data (Green \& Thorogood, 2013). We adopted a child-centred approach, which emphasises children's voices, also reflected in our choice of simple, child-friendly participatory tools (Larkin, Watts, \& Clifton, 2006).

The study was funded by Plan International (PI) and focused on children who were part of their Sponsorship Programme. Children (0-18 years old) are eligible for sponsorship if they reside in areas where PI Nepal operates and meet other criteria for inclusion (typically poverty or other forms of vulnerability). While historically PI has provided direct support to sponsored children, it now focuses on communitylevel initiatives (e.g. awareness campaigns on the benefits of education and funding to some schools, including special/resource schools). While these initiatives may have benefited some children in the sample, the majority of children were not attending schools receiving Plan support. Staff from PI were not present at any interviews (except where they were interviewees), nor involved in the analysis or interpretation of study findings.

\section{Ethical considerations}

Ethical approval for this study was granted by the London School of Hygiene \& Tropical Medicine (LSHTM) and the Nepal Health Research Council in August 2014. Before the start of each interview, informed written consent was received from stakeholders, guardians and older children. For younger children and children with 
communication/intellectual impairments, a simplified oral assent was sought, and pictorial child-friendly information sheets were provided. All names of children have been changed in order to maintain confidentiality.

\section{Recruitment and data collection}

Data collection was conducted in September 2014 in the districts of Sunsari, Makwanpur and Morang in Nepal. The districts were selected from the six districts where PI was active at the time of the study. Together they comprise a mix of geographies (Tera versus hills areas) and were accessible during the timeframe of the study. An advisory group in Nepal (National Disabled Youth Network) provided valuable input into topic guides and feedback on emergent themes.

\section{Children and guardians}

The sample was drawn from PI Nepal's 2012 dataset of 38,450 sponsored children, which identified 259 children with disabilities $(0.7 \%$ of sponsored children) (Plan International, 2014). Disability was reported by the primary guardian during annual interviews through the following question: "Does the sponsored child have an impairment/medical condition that can lead to disability?"

Sample selection was carried out by researchers from LSHTM using datasheets with basic demographic information of sponsored children. Twenty-one children were purposely selected based on the following criteria: being of schoolgoing age (6-17 years); representation of different impairment type (intellectual, physical, hearing and visual impairment); gender; age; district of residence (Makwanpur, Sunsari and Morang); and school status (in versus out of school).

Children and their primary guardian were interviewed separately, usually in the home environment, which was familiar to them, and where it was considered 
they would feel comfortable to talk about school issues. However, if a child was unable to communicate independently or requested the presence of his/her guardian, then guardians were invited to join the interview. Key topics covered in the guardian interviews included: (i) family background, (ii) child's condition, abilities and overall health, and (iii) child's education, including experience in school and or/reasons for non-attendance.

Child interviews focused on positive and negative experiences at home and at school. A participatory tool called the 'Feeling Dice' (Messiou, 2008) was used to help prompt discussion and increase comfort levels with younger children and older children with intellectual impairments. The different sides of the dice depict simple faces with different emotions (happy, sad, joyful, angry), which the children can draw themselves, and when the dice is thrown it prompts a discussion. Information about the communication abilities of the children were sought in advance of the interview to allow for appropriate adaptations (e.g. providing sign language interpretation, visual aids, adaptation of questionnaires). There were extremely rich interviews with some children, but there were also a number of challenges around ensuring that the children's voices were fully represented. For example, only one child with a profound hearing impairment had formal sign language training. Similarly, interviews with children with intellectual impairment and/or communication difficulties were more limited in scope. In six cases (four children with severe intellectual impairment, two children who were deaf but had no knowledge of sign language), interviews were not possible after several attempts with available supports (e.g. sign language interpretation, visual aids, assistance of other family members). In these instances, guardians or siblings provided additional information. 
All interviews were conducted in Nepali and lasted approximately 30-45 minutes for children and 45-60 minutes for guardians. All guardian and some child interviews were recorded, translated and transcribed. Some children's interviews were more participatory in nature and involved the use of sign language; in these cases, detailed notes were taken and crosschecked for accuracy with the Nepali research assistant and translator.

Stakeholders and school visits

Stakeholders included government, DPO representatives, school teachers and PI staff from the three districts, and from Kathmandu. Detailed notes were taken and these were crosschecked against the recordings, as necessary for quotes. Interviews were conducted mainly in English, with some Nepali. Furthermore, observational visits were made to two special schools for the hearing impaired, one integrated school for children with intellectual impairments, and one mainstream school.

\section{Sample}

In total, 21 families were visited, producing 20 guardian and 15 child interviews. Characteristics of the study sample can be found in Table 1. By gender, there were twice as many girls $(n=14)$ as boys $(n=7)$. This overrepresentation of girls is reflective of the total population of sponsored children with disabilities within the three districts visited (61\% female overall compared to $66 \%$ in the sample), as PI has targeted girls for sponsorship due to their greater exclusion from education and social participation. Median age of the children was 14 years. Most impairments could be characterised as moderate to severe. 
Of the 12 children who had enrolled in school, all but one attended a mainstream school for at least part of their schooling. A further two had attended special schools and one had gone to an integrated school, all for short periods of time ranging from a few months to two years. Nineteen stakeholder interviews and small group discussions were conducted with government officials, DPO leaders, PI Nepal staff, and teachers.

\begin{tabular}{|c|c|}
\hline Characteristics & n \\
\hline Gender & \\
\hline Boys & 7 \\
\hline Girls & 14 \\
\hline School status & \\
\hline In school & 12 \\
\hline Out of school & 9 \\
\hline - Dropped out & 8 \\
\hline - Never been & 1 \\
\hline Impairment type & \\
\hline Multiple & 9 \\
\hline - Includes intellectual & 8 \\
\hline o Includes physical & 6 \\
\hline - Includes vision & 2 \\
\hline - Includes hearing & 2 \\
\hline Physical (only) & 5 \\
\hline Intellectual (only) & 4 \\
\hline Vision (only) & 1 \\
\hline Hearing (only) & 2 \\
\hline School characteristics & \\
\hline $\begin{array}{l}\text { Children who have repeated a } \\
\text { grade }\end{array}$ & 7 \\
\hline $\begin{array}{l}\text { Children upgraded without } \\
\text { passing }\end{array}$ & 8 \\
\hline $\begin{array}{l}\text { Age for grade difference } \\
\text { compared to national standards } \\
\text { (in years) }\end{array}$ & 5 \\
\hline $\begin{array}{l}\text { Age for grade difference } \\
\text { compared to siblings (in years) }\end{array}$ & 2 \\
\hline
\end{tabular}




\section{Data analysis}

After each day of fieldwork, interview notes were reviewed by the lead field researcher $(\mathrm{LMB})$ and the local research assistant to identify any gaps in the interview schedule that needed to be addressed and to clarify emergent themes.

Thematic analysis was undertaken; the two lead researchers (LMB and MZ) read all transcripts, notes and observations to develop a coding framework. Inductive, open coding of notes/transcripts then was used to identify important features in the data (Boyatzis, 1998). Codes were then grouped into themes and sub-themes. Comparisons and inter-relationships between codes and categories was explored throughout the analysis (Green \& Thorogood, 2013).

\section{FINDINGS}

The factors that affect children with disabilities' access to and experience in school are complex: often a combination of individual, family, school and societal level factors were at play, with different implications for every child. The additional influences of gender, poverty and other elements frequently worked in synergy with impairment-related factors to compound or mitigate exclusion. Overall, key themes were: (a) social/attitudinal factors, (b) institutional factors, (c) economic factors, and (d) health and impairment-related factors. The classification of barriers and facilitators into these categories is based on the conceptualisation of disability outlined in the International Classification of Functioning, Disability and Health, reinforced in the UNCRPD, which views disablement as being exacerbated or mitigated through the interplay of a range of attitudinal, environmental, institutional, and other contextual factors (World Health Organization, 2001). 


\section{Social/attitudinal factors}

Positive Attitudes

An overwhelming finding was children's enthusiasm for going to school, expressed by the children themselves as well as their guardians. Getting to school might be physically extremely difficult, they may be struggling to understand the teacher and to communicate, they might have to constantly repeat grades, and they may be bullied, and yet most of them still wanted to attend. Children and guardians reported enjoyment of their lessons, being with other children, and a hope that education could lead to a better future as primary motivators.

I like everything about school - the teachers, the other children... I like computer science the most because the words are new...I want to keep going further with my education...it's ok if I have to leave my family, I just want to go.

Boy, age 14, who is a double amputee and in secondary school

The motivation for education was also underlined when children found they could no longer attend school. One mother described how her 17-year-old daughter, who has learning and communication difficulties, kept on repeating grade 1 , yet "she was very fond of learning. Even now, at home, she would get a notebook and pen and write on her own." The teachers, however, asked her daughter not to return to school. Her daughter smiles and laughs when she talks about her old school: "I miss reading and writing the most. I feel angry that I can't go back to school." More troubling, a 12-year-old girl with a physical impairment, who "liked everything about school" but was unable to transition to secondary school, tried to commit suicide 
from drinking pesticides. Her mother felt that her daughter's immense sadness and frustration at dropping out of school was a contributing reason.

\section{Different expectations of guardians and teachers}

While on one hand, guardians were aware of their child's desire to attend school, they, along with teachers, commonly questioned whether children with disabilities could receive or were indeed receiving a meaningful education. Consequently, some guardians did not see the utility of sending their children to school, the need for regular attendance or diligence in studies. Additionally, some teachers were reluctant to invest energy into teaching students with disabilities. These attitudes appeared to be particularly pronounced for children with intellectual impairments and/or with behavioural problems.

[Why doesn't she go to school?] She doesn't hear anything that's why...She is dumb, what should I say! I don't know if she would be able to learn.

Mother of a girl, age 15 with hearing and intellectual impairments (304)

[The community] thinks children with disabilities are useless, a burden and don't realise their potential...teachers aren't willing to enrol children with disabilities, [so] when they try to enrol, they get discouraged.

NGO staff member

Teachers' understanding of and attitude towards the child's impairment, appear to be important reasons for attendance. Teachers and guardians sometimes did not believe children with disabilities, particularly children with behavioural 
problems, should be included in mainstream schools. Tellingly, all the children in the sample who exhibited behavioural challenges were no longer in school and in all cases the school suggested or explicitly requested that the child not be sent to school.

She just used to dance in school and she didn't attend the classes. Other children just used to come out of class to watch her... When I talked to the teachers, they said other children get distracted, so she should not be sent to school. I think it would be helpful if she could be sent to some special school or organisation...The teachers said not to send her, so we can't do anything with that. And I think that she is disturbing others in school.

Father of a 14-year-old girl, with intellectual and mild physical impairments

Stigma, discrimination and violence

For a large proportion of children, discrimination, abuse and violence emerged as a dominant theme in their lives - in the classroom, on the journey to school, and in the community. It was highlighted by children and guardians alike, even without any probing on this issue. Interestingly, in contrast, it was not a common barrier highlighted by stakeholders.

Overall, two thirds of families (child and/or guardian) reported bullying and violence in school. Guardians always reported that their child with a disability was bullied more than their other children. Siblings and friends at the same school also confirmed the greater level of bullying and violence experienced by children with disabilities. Both teachers and peers were reported to be the perpetrators of such 
abuse. Those with communication impairments appeared to be particularly vulnerable as they were most likely not in a position to explain what was happening.

I didn't like anything about school, I had no friends... [the other students] would lock me in a room, call me dumb, 'lati', kick me and pull my hair...There was one teacher, a fat one, who beat me the most, he beat me because I couldn't understand what he was saying.

Girl, age 17, with a profound hearing impairment discussing her time at a mainstream school, via sign language interpreter (205).

The pervasiveness of stigma, discrimination and violence extended into the communities, reflected in the variety of derogatory and stigmatising terms used to describe children with disabilities, bullying, and in some cases parental abandonment.

Someone shouts at me and calls me 'cross-eyed' ("deri") and pulls my hair. [How many times has he said this to you?] Many times, 20 times.

Girl, age 12 with a physical and intellectual impairment (306)

Furthermore, sexual violence and rape emerged as an aspect of community violence and discrimination perpetrated against children - particularly girls - with disabilities. One young deaf woman interviewed was reported as having been recently raped by a neighbour and her teacher explained that children who were deaf at her school were especially vulnerable to rape because they were not able to shout out whilst being violated, and/or had difficulty in communicating their experiences and advocating for themselves.

Inclusion with peers 
Nonetheless, for some, schools provided friendships. Inclusion with peers continually reoccurred as both a powerful influence for children wanting to attend school or as a deterrent to return or continue if their friends had dropped out or they were behind in school. Due to late starts in school, gaps in schooling or frequent grade repetition, some children - namely children with intellectual impairments were significantly older than their peers. For example, one 14-year-old boy who had developed back problems explained that he did not want to return to the school he had dropped out of as he didn't think it would be useful and "I would be in grade 3 , with just small kids ...I would miss being with my friends."

\section{Institutional factors}

\section{Assessment of learning}

Over a third of the children in the sample who had ever been to school had repeated at least one grade. On average, these children were five grades behind for their age. Their siblings also were behind in their schooling; however, the difference in age-for-grade between children and their siblings was still two full years.

Additionally, there was a more hidden - and common - indicator that the learning of children with disabilities was not being adequately supported or assessed. Over a third of children with disabilities were upgraded to higher grades without passing:

She repeated three times second or third grade. She can't really take her exams properly so there isn't any proper grading. The teachers upgraded her along with her friends...She can't read and learn. [At first] the teachers 
thought it would help her to learn better if she would repeat the same grade, but now she is upgraded to another class [even though she didn't pass].

Mother of a girl, age 12, who has intellectual and mild visual impairments

Typically, enrolment rates and grade levels completed are used as benchmarks for gauging participation and equality in education. However, the experience of children in this study suggests that these are not necessarily good indicators .

\section{Lack of resources for inclusive education}

Lack of specialist resources, adapted curriculum and teacher training were highlighted by stakeholders as system-wide challenges to providing a quality education for children with disabilities, particularly in mainstream schools. Although there has been scale-up in recent years, teachers in mainstream schools receive minimal disability-specific training. The curriculum is often not adapted, or supported through specialist resources, to facilitate the teaching of children with different impairments. These issues were reflected in the descriptions provided by guardians, in particular, around the experience of children with communication difficulties and/or behavioural issues. Some guardians and teachers themselves indicated school staff felt overwhelmed, or that they did not have the capacity or resources to educate or manage children with disabilities in the classroom.

Even in integrated and special schools, resources are often inadequate. For integrated schools, only the teacher in the resource classroom receives mandatory 45-day disability-specific training. While there is some expectation that the resource teachers will train other teachers in the school, stakeholders reported that there is no 
formal process or requirement to do so. Children with hearing impairments in particular struggled to adjust as teachers in the mainstream - and even resource classrooms - rarely have sufficient proficiency in sign language.

In the [previously attended integrated school] it was difficult to understand the teacher because he just used natural signs. He didn't have any [formal] sign language skills...maybe because he is old he couldn't learn sign language.

Student at a special school for the hearing impaired, via sign language interpretation (118)

However, some schools visited were able to provide a more supportive learning environment for children with disabilities. For example, at one special school for children with profound hearing impairments, most children appeared to have a high fluency in sign language, were literate and reported receiving instruction in employment-relevant skills such as computer science, math and basic sciences. Similarly, one resource classroom for children with intellectual impairments had an instructor with extensive experience and training on special education, and the classroom was well stocked with specialist educational resources. It is important to note, however, that in both instances, schools received additional funding and resources from non-governmental sources.

\section{Limited inclusion}

Although integrated schools place an emphasis on integration within the wider school, in practice, many children remain segregated in resource classrooms. Segregation continued outside of the classroom as well, as one father explained that 
his daughter, who was at an integrated school, was taught in a different compound and had separate break times from children in the mainstream classes.

Attendance at residential schools also had implications for inclusion in the home and community, illustrated by one teacher in a resource classroom for children with intellectual impairments who explained: "There's no parent training or involvement about their child's disability". The result of this could be exclusion at home, explained by one girl with a profound hearing impairment who had attended a special school and described her isolation when she left school, as "at home, people don't understand my language."

\section{Parental concerns on safety}

In many cases, guardians were reluctant to send their child to school as they said they feared their child would not receive adequate care and protection. These fears were especially for children in residential settings. Guardians expressed that they would miss their child or worried that their child was too young to be living away from home. Safety was a major concern, particularly for girls:

There were only boys in the [integrated] school, who teased her. In total there were six students and she was the only girl there...There weren't any girls, so she might have felt alone.

Mother of a girl, age 12, who has a profound hearing and mild visual impairments (315) 
The hostel was dirty, kids were hungry and there was not a good air. I heard that a child had died because of carelessness. I'm not interested in putting Aakash in this type of school.

Mother of a 14-year-old boy with an intellectual impairment talking about her experience of visiting a special school (311)

\section{Physical accessibility}

For children whose impairments severely restricted mobility, getting to school and moving around school was reported as a challenge, particularly if they did not have an assistive device.

I don't have trouble getting around school on my wheelchair. But when it's not working, my friends need to help me get around... The wheelchair is useful for getting to class, the bathroom. [Without it] I need help to do these things.

Boy, age 14 , who is a double amputee, explaining how he gets around at his secondary school (308)

Stakeholders also reinforced the difficulties surrounding physical accessibility in schools. They noted that the lack of disability-friendly infrastructure, such as ramps and toilet facilities, could dissuade children, particularly with severe visual or mobility limitations from attending.

A more common barrier to physically accessing schools was travel, which was cited by a third of families as a reason for non-attendance or absenteeism. The problem was more pronounced for children with mobility limitations, and children 
attending secondary schools or special schools, which were at a greater distance from the home.

During the rainy days, she can't walk...she can't balance herself when the floor is wet. Sometimes she falls even if the floor is dry....she misses around 3 months of school in a year...We don't let her go to school during the rain...I am worried that if she falls and something happens to her, others would blame me for not taking care of her, as she is not our own child.

Aunt discussing her niece, age 14, who has mobility limitations and an intellectual disability (313)

Stakeholders noted that challenges associated with travel to school are likely to vary in intensity throughout Nepal, with mountain and hill regions likely posing the greatest difficulties in getting to school due to the terrain and limited availability of schools.

\section{Economic factors}

Under Nepal's Constitution and other national policies, education is to be provided free of cost, however, many families still reported paying for uniforms, exams, stationary and other small fees for their children to attend school.

Disability scholarships are available to provide financial assistance to help children attend schools. However, to be eligible for a disability scholarship, children need to have a disability card, which some found difficult to obtain. Although several families expressed a desire to send their child to a special or integrated school, most assumed the costs would be prohibitive and were unaware of disability scholarships. 
Opportunity costs were also a persistent barrier. Notably, the cost of guardians' time in bringing their children to school was mentioned frequently, as guardians would often spend significant portions of their day taking their children to and from school, resulting in missed time at work. It also commonly resulted in missed days of school.

She couldn't continue her education because the transportation that was being provided by the school stopped... Now, as both me and my wife don't have much time out of our work, and she can't go on her own, it is difficult for us to drop her and fetch back from school every day...So, now her education stopped.

Father and mother of a girl, age 17, who has a profound hearing impairment (305)

Finally, in three cases, children with disabilities were kept out of school to work, both for work around the house (two girls), and for additional paid work outside (one boy). Interestingly, children and not guardians disclosed this information. It is possible that there was underreporting of being out of or missing school for work, and that guardians were unwilling to admit to this reason.

\section{Health and impairment-related factors}

Half of the guardians reported that their child was more frequently ill compared to their siblings. In some cases, guardians described how their child had always been more susceptible to ill health from birth. Guardians also expressed how difficulties in communication sometimes made it more challenging for their child to explain their illness. 
When she used to go to school, she would cry in the classroom because of pain. She can't communicate her problems [to others]...Even when she is ill she would go [to school]. When teachers found out she was not well, they would ask her to go back home and she would come back crying.

Mother of girl, age 17, with intellectual and communication impairments (302)

Poor health clearly has an impact on children's education; some regularly missed school, fell ill during class time and had much longer periods off school, sometimes for several months, because of on-going treatment and rehabilitation. Time out of school for longer periods resulted in a few children having to repeat grades. In contrast, for the small number of children who received assistive devices, rehabilitation and other needed healthcare, improvements in functioning led to increased well-being and participation - including in education.

\section{DISCUSSION}

This research presents one of the few pieces of in-depth qualitative research in Nepal on access to education for children with disabilities, focussing on the perspectives of children themselves and their guardians. Through exploring in detail the lived realities of these families, it highlights that the reasons children with disabilities are not attending, progressing or completing their education are complex, involving a mixture of attitudinal, institutional, economic and health-related factors.

Increasing research has noted that children with disabilities are less likely than their peers to attend school (Filmer, 2008; Kuper et al., 2014; Mizunoya et al., 2016), which carries implications for the fulfilment of SDG 4 and other national and 
international commitments on equity in education. Even when children with disabilities were attending school, however, this study highlights that many experienced difficulties in learning due to reasons such as high absenteeism or lack of resources to support inclusive teaching. Consequently, many were repeating grades, or more commonly, being upgraded without passing. Other research from Nepal (Barriga, 2011; Lamichhane, 2013; UNESCO, 2010) and India (Singhal, 2014) has reiterated these issues, wherein children may be enrolled, but their learning is not supported. Although Nepal has adopted policies that strive to increase access to schools and inclusivity in learning, implementation is still lagging. Particularly in rural areas, teachers may not have access to training or resources to provide an inclusive learning experience (Lamichhane, 2017). Resources to support the learning of children with profound hearing impairments was a particular concern, and this issue has been raised in other studies from Malawi and India (L. Banks \& Zuurmond, 2015; Prakash, 2012). The lack of sign language knowledge among children with profound hearing impairments also compounded exclusion at home, school and the community.

In addition to the academic experience, it is also imperative to consider the social experience of children with disabilities at school. On one hand, the desire to be included with peers was a powerful motivator for attending school. However, violence and bullying at school was a common experience in our study. Other studies from Malawi and Uganda similarly found frequent violence towards children with disabilities while in school (L. M. Banks, Kelly, Kyegombe, Kuper, \& Devries, 2017; K. M. Devries et al., 2014). Sexual violence also emerged as a pressing concern for girls with disabilities, mirroring other research (L. Banks \& Zuurmond, 2015; L. M. Banks et al., 2017; K. M. Devries et al., 2014). For example, in one study 
in Uganda, almost a quarter of girls with disabilities experienced sexual violence while at school, which was significantly higher compared to girls without disabilities (K. M. Devries et al., 2014). Addressing violence towards children with disabilities both in and outside of school, such as through promoting inclusivity in communitybased and government-sponsored child protection mechanisms, is an area in need of further exploration (L. M. Banks et al., 2017; K. Devries et al., 2018).

Further, it is important to acknowledge the tendency of educational debates to homogenise the experience of children with disabilities. This study found dominant barriers often varied by impairment type, which highlights the necessity of clearly defined impairment-specific strategies. For example, this research highlighted that while all children with disabilities face exclusion, children with intellectual impairments appear to be more vulnerable to exclusion, both socially and educationally. The high proportion of children with intellectual impairments out of school is reflected in analyses of Nepal census data (UNICEF, 2016), as well as from other countries (Kuper et al., 2014; Nidhi Singal, 2015). Even when children with intellectual impairments do attend, negative attitudes by peers and teachers alike are common, as is scarcity of specialist resources and teacher training (L. Banks \& Zuurmond, 2015; Barriga, 2011).

Similarly, there is also a need to explore the intersectionality between disability and other sources of marginalisation, such as gender and poverty. Notably, safety concerns were greater for girls with disability, which affected schooling decisions. More broadly growing evidence suggests that girls with disabilities are most likely to be excluded and our research strengthens the argument that inclusive education efforts also need to be gender sensitive (N Singal, 2018; United Nations Girls' Education Initiative \& Leonard Cheshire Disability, 2017). Similarly, many 
children in the sample were living in poverty, or belonged to other traditionally excluded groups from education in Nepal (e.g. Dalit caste, Muslims) (Khanal, 2015; United Nations, 2011), which may have further compounded their risk of exclusion from school or experience in the classroom, although caste was not explored in any detail in this study.

While important strides have been made in both policy and practice to improve inclusive education in Nepal, gaps remain. This study and others have emphasised many institutional and policy-related challenges, such as the need to improve teacher training, availability of specialist resources, physical accessibility of schools and adapt curriculums (Barriga, 2011; UNESCO \& Government of Nepal, 2015; UNICEF, 2016).

This study also highlights the importance of acknowledging the central role of parents as partners in efforts towards inclusive education (Nidhi Singal, 2016). Parents, as seen in our research, were largely supportive of, and instrumental in, getting their child with disabilities in school and realised that it made their child happy and was important for their future, but were also aware of the lack of education and general neglect faced by their child in school. Parents are important enablers in the system and must be supported to hold teachers and systems accountable.

Additional interventions are needed to change the culture of schools, communities and families to support social inclusion of children with disabilities. Further, establishing coordinated, cross-sectorial responses with actors outside of the education sector are required to address other barriers to inclusive education. For example, reducing violence towards children with disabilities in and out of school will require involvement of child protection bodies, while social protection 
programmes - particularly disability scholarships - can help tackle economic barriers to participation. Additionally, addressing the nexus between disability, poor health, unmet rehabilitation needs and education will require multi-sectorial collaborations, such as inputs from health and rehabilitation services. The World Health Organization's Global Disability Action Plan recognises the importance of assistive devices and timely access to rehabilitation as essential for supporting participation in education (World Health Organization, 2015), although growing evidence suggests children with disabilities face challenges in accessing these essential services (Nesbitt, Mackey, Kuper, Muhit, \& Murthy, 2012).

Finally, as noted earlier in the paper, the focus on engaging with the perspectives and experiences of children with disabilities was an important contribution of this research, and the data presented above highlights the important insights which can be gathered when we move beyond simply focusing on enrolment numbers and attitudes of others, to understanding how children and their families experience schooling, or indeed the lack of it. These voices are central in contributing to the on-going debates on how to achieve SDG 4 so as to "ensure inclusive and equitable quality education...for all." Further research is needed to develop strategies to support the participation of children with complex needs, particularly children with severe communication challenges.

\section{Acknowledgments}

We would like to thank Shubha Kayastha, who provided superb translation and research assistance in all interviews. Additionally, we would like to thank Prem Aryal and Shusil Joshi from Plan International Nepal, who were instrumental in organising this research, and to Aidan Leavy and, Linda Campbell for their advisory role. A particular thank you to all the children and their guardians who gave their time to contribute to the research. 
Funding body: This work was supported by the Plan International.

\section{References:}

Banks, L., \& Zuurmond, M. (2015). Barriers and enablers to inclusion in education for children with disabilities in Malawi: Norwegian Association of Disabled: Oslo, Norway.

Banks, L. M., Kelly, S. A., Kyegombe, N., Kuper, H., \& Devries, K. (2017). "If he could speak, he would be able to point out who does those things to him": Experiences of violence and access to child protection among children with disabilities in Uganda and Malawi. PloS one, 12(9), e0183736.

Barriga, S. R. (2011). Futures stolen : barriers to education for children with disabilities Retrieved from New York: http://www.hrw.org/reports/2011/08/24/futures-stolen

Boyatzis, R. E. (1998). Transforming qualitative information: Thematic analysis and code development: sage.

Cambridge Education Ltd, \& METCON Consultants. (April 2009). Joint Evaluation of Nepal's Education for All 2004-2009 Sector Programme. Retrieved from http://www.norad.no/en/tools-and-publications/publications/publication?key=125146

Devries, K., Kuper, H., Knight, L., Allen, E., Kyegombe, N., Banks, L. M., . . . Naker, D. (2018). Reducing physical violence toward primary school students with disabilities. Journal of Adolescent Health, 62(3), 303-310.

Devries, K. M., Kyegombe, N., Zuurmond, M., Parkes, J., Child, J. C., Walakira, E. J., \& Naker, D. (2014). Violence against primary school children with disabilities in Uganda: a cross-sectional study. BMC public health, 14(1), 1017.

Eide, A. H., Neupane, S., \& Hem, K.-G. (2016). Living conditions among people with disability in Nepal. Retrieved from Trondheim, Norway:

Filmer, D. (2008). Disability, poverty, and schooling in developing countries: results from 14 household surveys. The World Bank Economic Review, 22(1), 141-163.

Government of Nepal. (2006). National Policy and Plan of Action on Disability. Kathmandu.

Government of Nepal. (2015). The Constitution of Nepal. Kathmandu, Nepal.

Green, J., \& Thorogood, N. (2013). Qualitative methods for health research: Sage.

Groce, N., Kembhavi, G., Wirz, S., Lang, R., Trani, J.-F., \& Kett, M. (2011). Poverty and Disability: A critical review of the literature in low and middle-income countries.

Groce, N. E., \& Trani, J.-F. (2009). Millennium Development Goals and people with disabilities. The Lancet, 374(9704), 1800-1801.

Khanal, D. (2015). Children from the Dalit community in rural Nepal: a challenge to inclusive education. International Journal of Inclusive Education, 19(7), 710-720.

Kuper, H., Monteath-van Dok, A., Wing, K., Danquah, L., Evans, J., Zuurmond, M., \& Gallinetti, J. (2014). The Impact of Disability on the Lives of Children; Cross-Sectional Data Including 8,900 Children with Disabilities and 898,834 Children without Disabilities across 30 Countries. PloS one, 9(9), e107300.

Lamichhane, K. (2013). Disability and barriers to education: evidence from Nepal. Scandinavian Journal of Disability Research, 15(4), 311-324.

Lamichhane, K. (2017). Teaching students with visual impairments in an inclusive educational setting: a case from Nepal. International Journal of Inclusive Education, 21(1), 1-13.

Lamichhane, K., \& Okubo, T. (2014). The nexus between disability, education, and employment: Evidence from Nepal. Oxford Development Studies, 42(3), 439-453.

Lamichhane, K., \& Sawada, Y. (2013). Disability and returns to education in a developing country. Economics of Education Review, 37, 85-94.

Larkin, M., Watts, S., \& Clifton, E. (2006). Giving voice and making sense in interpretative phenomenological analysis. Qualitative research in psychology, 3(2), 102-120. 
Messiou, K. (2008). Encouraging children in more inclusive ways. Brit J Spec Ed, 35(1), 2632.

Miles, S., \& Singal, N. (2010). The Education for All and inclusive education debate: conflict, contradiction or opportunity? International Journal of Inclusive Education, 14(1), 1-15.

Ministry of Education of the Government of Nepal. (2009). School Sector Reform Plan 20092015. Kathmandu.

Mitra, S., Posarac, A., \& Vick, B. (2013). Disability and poverty in developing countries: a multidimensional study. World Development, 41, 1-18.

Mizunoya, S., Mitra, S., \& Yamasaki, I. (2016). Towards Inclusive Education: The impact of disability on school attendance in developing countries.

Nesbitt, R., Mackey, S., Kuper, H., Muhit, M., \& Murthy, G. (2012). Predictors of referral uptake in children with disabilities in Bangladesh-Exploring barriers as a first step to improving referral provision. Disability and rehabilitation, 34(13), 1089-1095.

Plan International. (2014). Include us in education! . Retrieved from https://planinternational.org/include-us-disability-inclusion-education

Prakash, S. S. (2012). Inclusion of children with hearing impairment in schools: A survey on teachers' attitudes. Disability, CBR \& Inclusive Development, 23(3), 90-111.

Sharma, U., \& Das, A. (2015). Inclusive education in I ndia: past, present and future. Support for Learning, 30(1), 55-68.

Singal, N. (2008). Working towards inclusion: Reflections from the classroom. Teaching and Teacher Education, 24(6), 1516-1529.

Singal, N. (2015). Education of children with disabilities in India and Pakistan: An analysis of developments since 2000: Background paper for GMR.

Singal, N. (2016). Schooling children with disabilities: Parental perceptions and experiences. International Journal of Educational Development, 50, 33-40.

Singal, N. (2018). Making girls with disabilities count in the inclusive education agenda. Retrieved from https://medium.com/ungei-blog/making-girls-with-disabilities-count-inthe-inclusive-education-agenda-d14e4d05a4ac

Singal, N., Bhatti, F., \& Janjua, S. (2012). Increased expectations, unrealised gains: educational outcomes for young people with disabilities in India and Pakistan. In C. Colough (Ed.), Education Outcomes and Poverty in the South: A Reassessment. London: Routledge.

Singal, N., \& R. Jeffery. (2011). Inclusive education in India: the struggle for quality in consonance with equity. In A. J. Artiles, E. B. Kozleski, \& F. R. Waitoller (Eds.), Inclusive Education: Examining Equity on Five Continents. Massachusetts.: Harvard Education Press.

Singal, N., Ware, H., \& Khanna-Bhutani, S. (2017). Inclusive Quality Education for Children with Disabilities. Report prepared for the World Innovation Summit for Education, Doha. Retrieved from https://www.wise-gatar.org/2017-wise-research-inclusiveeducation-children-disabilities

Singhal, N. (2014). Role of schooling in enhancing children's personal, social and educational well-being. Final Report for CBM. Retrieved from

UNESCO. (2010). Education for All Global Monitoring Report: Reaching the Marginalised. Retrieved from Paris, France:

UNESCO, \& Government of Nepal. (2015). Education for All: National Review Report 2001 2015. Retrieved from Kathmandu, Nepal:

UNICEF. (2016). Global Initiative on Out-of-School Children: Nepal Country Study. Retrieved from Kathmandu, Nepal:

United Nations. (2011). Nepal - A Country Analysis With a Human Face. Retrieved from Kathmandu: http://un.org.np/sites/default/files/Nepal CountryAanalysis 2011 Feb2013.pdf

United Nations. (2015). Sustainable Development Goals. Retrieved from https://sustainabledevelopment.un.org/?menu=1300

United Nations. (2018). Goal 2: Achieve Universal Primary Education. Retrieved from http://www.un.org/millenniumgoals/education.shtml 
United Nations Girls' Education Initiative, \& Leonard Cheshire Disability. (2017). Still left behind: Pathways to inclusive education for girls with disabilities. Retrieved from London, UK:

WHO, \& World Bank. (2011). World Report on Disability Retrieved from Geneva available at http://www.who.int/disabilities/world report/2011/en/index.html: http://www.who.int/disabilities/world report/2011/en/index.html

World Health Organization. (2001). International Classification of Functioning, Disability and Health: ICF: World Health Organization.

World Health Organization. (2015). WHO global disability action plan 2014-2021: Better health for all people with disability. Geneva, Switzerland: World Health Organization. 